\title{
CHANGES OF INTERLEUKINS IN PATIENTS WITH NOSOCOMIAL PNEUMONIA AGAINST A BACKGROUND OF TRAUMATIC BRAIN INJURY: ROLE IN THE DIAGNOSIS AND MONITORING OF DISEASE
}

\author{
Anastasiia Ilchenko \\ Department of Clinical Pharmacy and Clinical Pharmacology \\ National Pirogov Memorial Medical University, Vinnytsya \\ 56 Pyrohova str., Vinnitsa, Ukraine, 21018 \\ Zhytomyr Regional Clinical Hospital named after O. F. Herbachevsky \\ 3 Chervonoho Khresta str., Zhitomir, Ukraine, 10002 \\ kalypsol@rambler.ru
}

\begin{abstract}
Introduction. Nosocomial pneumonia (NP) is the second leading frequency and mortality among nosocomial infections. NP is a frequent complication of severe traumatic brain injury (TBI). The difficulty in diagnosis and monitoring of disease NP on the background of TBI is that the usual signs NP "masked" manifestations of the underlying disease.

The aim of our study was to improve the diagnosis and assess the effectiveness of the treatment of nosocomial pneumonia with clarithromycin by studying of serum interleukins in patients with nosocomial pneumonia on the background of traumatic brain injury.

Materials and methods. We determined levels of TNF $\alpha$, IL-4, IL-6, IL-8, IL-10. We examined 45 patients with isolated TBI, 44 patients with NP (standard treatment scheme), 49 patients with NP, each therapy with clarithromycin. The control group was 33 relatively healthy people.

Conclusions. The study revealed a significant increase in the concentration of interleukin TNF $\alpha$, IL-6, IL-8, IL-10 in the serum of patients with NP on the background of TBI compared with patients with isolated TBI and healthy individuals. Our study found significantly lower concentrations of interleukin TNFa, IL-6, IL-8, IL-10 in the serum of patients after treatment with the addition of clarithromycin compared with patients with standard therapy.
\end{abstract}

Keywords: nosocomial pneumonia, traumatic brain injury, diagnosis, cytokines, clarithromycin.

\section{Introduction}

Nosocomial pneumonia (NP) is the second in frequency and the first in mortality among nosocomial infections. NP is one of the most common and dangerous infectious complications of severe traumatic brain injury (TBI). According to many researchers, GP develops in 20-60\% of cases of TBI. The clinical diagnosis of nosocomial pneumonia, diseases of the central nervous system in general and in particular TBI, remains a challenge that continues to develop [1-5]. Late diagnosis is one of the causes of complications and lethal outcome in this group of patients with clinical signs of pneumonia, hidden symptoms of the underlying disease, severity of general cerebral and focal neurological symptoms [1, 4-7]. Clinical signs NP include a local lung inflammation, extrapulmonary manifestations of pneumonia, laboratory and radiological changes; all the criteria listed above are nonspecific. Fever and leukocytosis often accompany an isolated head injury. $\mathrm{Pu}-$ rulent sputum from the trachea may indicate only the colonization of the upper respiratory tract. Not informative conventional X-ray may be associated with localized pneumonic foci in remote places [8-9]. Complication of NP diagnosis in this patient and the severity of the underlying disease, neurological symptoms and the need for prolonged use of mechanical ventilation are typical. That is why the search for markers of inflammation for the diagnosis and monitoring of NP on the background of TBI using informative and, if possible, non-invasive methods is urgent [1, 10-13].

Among the various pathogenic factors contributing to the occurrence, effects and peculiarities of pulmonary pathology, many authors identify violations of immunological reactivity and imbalance mediators of intercellular interactions. In recent years the role of cytokines as key mediators of inflammation is widely discussed $[14,15]$. The main mediators recognized damaged lung tumor necrosis factor alpha (TNF $\alpha$ ), interleukin 1 (IL-1), interleukin 6 (IL-6), interleukin 
8 (IL-8); among cytokines with anti-inflammatory properties the leading role is played by interleukin 10 (IL-10). In diseases of the lung cytokines the data, included in the infectious-inflammatory process at their own immune effector mechanisms and managers, largely determine the direction, severity and outcome of pathological process [1-2, 16-19].

Relatively pneumonia, as a separate nosology, is enough publications that clearly confirm the production of interleukins, both locally and in the systemic circulation in response to lipopolysaccharide complexes microorganisms [3, 7, 18-20]. According to the scientists, determination of the level of interleukin has diagnostic value, because the concentration of cytokines in the blood adequately reflects the severity of inflammation $[7,8,15,17]$. However, to date there is no study of the diagnostic role of cytokines in nosocomial pneumonia against the background of TBI. Therefore, to assess the pathogenetic role of interleukins and their diagnostic value, we studied the contents of TNF $\alpha$, I IL-6 and IL-8 in serum of patients with NP on the background of TBI and their changes in the dynamics of the treatment process $[1,5,19-21]$.

\section{Aim}

Improve the diagnosis and assess the effectiveness of the treatment of nosocomial pneumonia by studying of serum interleukins in patients with nosocomial pneumonia on the background of traumatic brain injury.

\section{Materials and Methods}

The study was conducted in 138 patients aged 18 to 83 years, who were treated in departments of intensive care neurosurgery and neurosurgery Zhytomyr Regional Clinical Hospital, named after O. F. Herbachevsky during 2013-2016.

The composition of Group 1 included 45 patients with severe TBI. The patients whose traumatic brain injury was complicated by the development of NP, were divided into two identical groups depending on the treatment. The structure of the second group included 44 patients with NP treated with medication according to the standard scheme (ceftazidime and levofloxacin). The structure of the Group 3 contained 49 patients who received standard therapy in addition to clarithromycin 500 $\mathrm{mg}$ two times daily by intravenous infusion. There is little known effect of clarithromycin in cases NP with regard to its indirect antimicrobial and immunomodulatory properties. The inclusion of immunomodulating treatment, contributing to the elimination of cytokine imbalance, as a component of adjuvant therapy in the pathogenesis NP is reasonable. Duration of treatment was 10 days. Patients of 2 and 3 groups underwent the interleukins control again on $10^{\text {th }}$ day of treatment.

Among the Group 1 of patients 38 people $(84.5 \%)$ were male, 7 persons $(15.5 \%)$ - women. The average age of patients in Group 1 was 49,2 $\pm 15,2$ years. Among patients Group $2-$ in accordance 36 men $(81.8 \%)$ and 8 women $(18.2 \%)$, among patients of Group $3-41$ persons $(83.7 \%)-$ men, 8 people $(16.3 \%)$ - women . The average age of patients in this group was $48,2 \pm 16,7$ years. Gender differences in the structure of the groups were not statistically significant $(p>0.05)$.

The diagnosis of pneumonia is established according to international recommendations and the current Ukrainian Protocol diagnosis and treatment of pulmonary disease in adults (Ukraine № 128 from 19.03.2007).

Determination of the levels of interleukin TNFa, IL-6, IL-8, IL-10 in serum was performed by ELISA using standard reagent kits A-8756 "TNF $\alpha$-IFA-BEST", measuring range: 0-250 pg/ml; A-8768 “IL-6-IFA-BEST", measuring range: 0-300 pg/ml; A-8762 “IL-8-IFA-BEST”, measuring range: $0-250 \mathrm{pg} / \mathrm{ml}$; A-8774 "IL-10 -IFA-BEST" measurement range: 0-500 pg/ml; produced by "Vector-Best", Russia. Settings regional standards were determined in 33 adult healthy subjects. The average age of 35,4 $\pm 16,1$ years, of which - 30 (87.9\%) men and 4 (12.1\%) women (control group). Blood sampling was carried out in equal conditions (in the morning on an empty stomach in the quantities of $5 \mathrm{ml}$ ). The data were analyzed using the standard methods of statistical analysis using a personal computer using the application package Microsoft Excel, Statistica 6. 0. Statistical analysis of the differences between the groups with regard to the nature of distribution was carried out using non-parametric test Mann-Whitney. 


\section{Results}

The following results of interleukins study were obtained. The were received the following indicators of regional norms: TNF $\alpha-0,94 \pm 0,24 \mathrm{pg} / \mathrm{ml}$ (range $0.40-1,28 \mathrm{pg} / \mathrm{mL}$ ), IL-6 - 1,24 $\pm 0,22 \mathrm{pg} / \mathrm{ml}$ (range 0.90 to $1.62 \mathrm{pg} / \mathrm{mL}$ ), IL- $8-1,50 \pm 0,61 \mathrm{pg} / \mathrm{ml}$ (range 0.5 to $2.6 \mathrm{pg} / \mathrm{ml}$ ), IL-10 - 1,61 $\pm 054 \mathrm{pg} / \mathrm{ml}$ (range 0.7 to $3.0 \mathrm{pg} / \mathrm{ml}$ ).

In group 1 were the following results interleukins: TNF $\alpha-3,21 \pm 0,67 \mathrm{pg} / \mathrm{ml}, \mathrm{IL}-6-4,88 \pm$ $\pm 1,65 \mathrm{pg} / \mathrm{ml}, \mathrm{IL}-8-3,93 \pm 0,95 \mathrm{pg} / \mathrm{ml}, \mathrm{IL}-10-4,63 \pm 3,07 \mathrm{pg} / \mathrm{ml}$.

The results of interleukins in groups 2 and 3, compared with healthy people, are presented in Table 1.

Table 1

Comparison of interleukins in groups 2, 3 and healthy people

\begin{tabular}{ccccccc}
\hline Parameter & Group 2 & Group 3 & Healthy person & p 2-3* & p H/P-2** & P H/P-3** \\
\hline TNFo, pg/ml & $6,42 \pm 5,41$ & $6,96 \pm 6,06$ & $0,94 \pm 0,24$ & $>0,05$ & $<0,0001$ & $<0,0001$ \\
IL-6, pg/ml & $59,04 \pm 69,52$ & $65,84 \pm 82,14$ & $1,24 \pm 0,22$ & $>0,05$ & $<0,0001$ & $<0,0001$ \\
IL-8, pg/ml & $53,11 \pm 61,55$ & $49,79 \pm 60,12$ & $1,50 \pm 0,61$ & $>0,05$ & $<0,0001$ & $<0,0001$ \\
IL-10, pg/ml & $13,60 \pm 21,15$ & $12,72 \pm 19,91$ & $1,61 \pm 0,54$ & $>0,05$ & $<0,0001$ & $<0,0001$
\end{tabular}

Note: *-statistically insignificant differences between the second and the third groups ( $p>0.05)$; ** - statistically significant differences between the healthy person and second or third groups $(p<0,0001)$

The results of interleukins in groups 2 and 3 before treatment and after treatment, compared with Group, are presented in Table 2.

Table 2

Comparison of interleukins in Group 2 and Group 3 with Group 1

\begin{tabular}{cccccc}
\hline Parameter & Group 1 & $\begin{array}{c}\text { Comparison Group 1 } \\
\text { with Group 2 Before } \\
\text { treatment }\end{array}$ & $\begin{array}{c}\text { Comparison Group } \\
\text { 1 with Group 2 After } \\
\text { treatment }\end{array}$ & $\begin{array}{c}\text { Comparison Group 1 } \\
\text { with Group 3 Before } \\
\text { treatment }\end{array}$ & $\begin{array}{c}\text { Comparison Group } \\
\text { 1 with Group 3 After } \\
\text { treatment }\end{array}$ \\
\hline $\mathrm{TNF} \alpha, \mathrm{pg} / \mathrm{ml}$ & $3,213 \pm 0,673$ & $0,005^{*}$ & $0,006^{*}$ & $0,028^{*}$ & $0,359 \#$ \\
$\mathrm{IL}-6, \mathrm{pg} / \mathrm{ml}$ & $4,888 \pm 1,659$ & $0,001^{*}$ & $0,023^{*}$ & $0,001^{*}$ & $0,430 \#$ \\
$\mathrm{IL}-8, \mathrm{pg} / \mathrm{ml}$ & $3,938 \pm 0,959$ & $0,001^{*}$ & $0,004^{*}$ & $0,001^{*}$ & $0,133 \#$ \\
$\mathrm{IL}-10, \mathrm{pg} / \mathrm{ml}$ & $4,638 \pm 3,075$ & $0,075 \#$ & $0,017^{*}$ & $0,011^{*}$ & $0,133 \#$
\end{tabular}

Note: \#- statistically insignificant differences ( $p>0.05) ;{ }^{*}$ - statistically significant differences $(p<0.05)$

Statistical comparison of the reliability of differences between groups 2 and 3 before treatment and after treatment (Table 3).

Table 3

Statistical comparison between groups 2 and 3 before treatment and after treatment

\begin{tabular}{cccccccc}
\hline Parameter & \multicolumn{3}{c}{ Group 2 } & \multicolumn{3}{c}{ Group 3 } \\
Before treatment & After treatment & $\mathbf{p}^{*}$ & Before treatment & After treatment & $\mathbf{p}^{* * *}$ & $\mathbf{p}^{* * *}$ \\
\hline TNF $\alpha$, & $6,420 \pm$ & $5,285 \pm$ & 0,502 & $6,960 \pm$ & $3,545 \pm$ & 0,118 & 0,002 \\
pg/ml & $\pm 5,413$ & $\pm 10,261$ & & $\pm 6,062$ & $\pm 1,044$ & \\
IL-6, & $59,040 \pm$ & $15,245 \pm$ & 0,264 & $65,840 \pm$ & $6,480 \pm$ & 0,004 & 0,004 \\
pg/ml & $\pm 69,523$ & $\pm 9,921$ & & $\pm 82,143$ & $\pm 3,953$ & & \\
IL-8, & $53,110 \pm$ & $12,990 \pm$ & 0,118 & $49,790 \pm$ & $5,970 \pm$ & 0,001 & 0,007 \\
pg/ml & $\pm 61,549$ & $\pm 8,130$ & & $\pm 60,116$ & $\pm 3,416$ & & \\
IL-10, & $13,600 \pm$ & $10,060 \pm$ & 0,823 & $12,720 \pm$ & $7,445 \pm$ & 0,823 & 0,330 \\
pg/ml & $\pm 21,152$ & $\pm 9,290$ & & $\pm 19,908$ & $\pm 5,166$ & &
\end{tabular}

Note: $p^{*}$ - statistically differences between the before treatment and after treatment in the second groupe; $p^{* *}$ - statistically differences between before treatment and after treatment in the third group; $p^{* * *}$ - statistically differences between the second group and the third group after treatment ( $p<0.05$ - statistically significant differences) 


\section{Discussion}

We received the values of control group of people in line with the average, obtained in the examination of serum of healthy donors by the manufacturer of test systems "Vector-Best".

Increased levels of cytokines in the group 1 relative to healthy subjects was statistically significant $(\mathrm{p}<0.0001)$, which is associated with the likely reaction to trauma and stress, but significantly lower than in groups 2 and 3.

The increase of the level of interleukin TNF $\alpha$, IL-6, IL-8 in group 2 and 3 before treatment is significantly higher than in group $1(\mathrm{p}<0.05)$. In group 2 after treatment (standard therapy) interleukin difference in levels compared with group 1 remains statistically significant $(\mathrm{p}<0.05)$. However, the results of interleukin TNF $\alpha$, IL-6, IL-8 in group 3 after treatment show no statistically significant difference compared to a group $1(\mathrm{p}>0.05)$. This shows the effectiveness of complementary therapy with clarithromycin, which was performed in group 3 . The difference is statistically significant TNF $\alpha$, IL-6, IL-8 in groups 2 and 3 after treatment $(\mathrm{p}<0.05)$.

\section{Conclusions}

The study revealed a significant increase in the concentration of interleukin TNF $\alpha$, IL-6, IL-8, IL-10 in the serum of patients with NP on the background of TBI compared with patients with isolated TBI and healthy individuals.

Quantitative changes in the concentration of serum interleukins in patients with NP on the background of TBI allow you to use these markers as additional laboratory criterion in specifying the diagnosis in these patients. Determination of cytokine status can be used to improve diagnosis in patients with TBI threatening complications such as nosocomial pneumonia.

In groups 2 and 3 (patients with NP) before treatment no significant difference in the levels of interleukins was revealed. So Groups 2 and 3 are identical by the level of cytokines TNF $\alpha$, IL-6, IL-8, IL-10. However, our study found significantly lower concentrations of interleukin TNF $\alpha$, IL-6, IL-8 in the serum of patients of Group 3 after treatment with the addition of clarithromycin compared with patients Group 2 (standard therapy).

Thus the use of clarithromycin in the treatment of nosocomial pneumonia on the background TBI has been effective, as it is evidenced by significant decrease in levels of interleukin TNF $\alpha$, IL-6, IL-8. The analysis of cytokine status is effective for monitoring the effectiveness of treatment of nosocomial pneumonia on the background of TBI.

\section{References}

[1] Guidelines for the Management of Adults with Hospital-acquired, Ventilator-associated, and Healthcare-associated Pneumonia (2005). American Journal of Respiratory and Critical Care Medicine, 171 (4), 388-416. doi: 10.1164/rccm.200405-644st

[2] Barbier, F., Andremont, A., Wolff, M., Bouadma, L. (2013). Hospital-acquired pneumonia and ventilator-associated pneumonia. Current Opinion in Pulmonary Medicine, 19 (3), 216-228. doi: 10.1097/ mcp.0b013e32835f27be

[3] Chuchalin, A. G. (2015). Pneumonia as an actual medical problem of the 21th century. Pulmonology, 25 (2), 133-142. doi: 10.18093/0869-0189-2015-25-2-133-142

[4] Feshchenko, Yu. I., Dziublyk, Yu. I., Simonov, S. S. (2012). Hospitalna (nozokomialna) pnevmoniia u doroslykh osib: etiolohiia, patohenez, klasyfikatsiia, diahnostyka, antybakterialna terapiia [Hospital (nosocomial) pneumonia in adults: etiology, pathogenesis, classification, diagnosis, antibiotic therapy]. Zdorovia Ukrainy, 1 (278), 35-36.

[5] Giamarellos-Bourboulis, E. J., Mylona, V., Antonopoulou, A., Tsangaris, I., Koutelidakis, I., Marioli, A. et. al. (2013). Effect of clarithromycin in patients with suspected Gram-negative sepsis: results of a randomized controlled trial. Journal of Antimicrobial Chemotherapy, 69 (4), 1111-1118. doi: 10.1093/jac/dkt475

[6] Gogos, C. A., Drosou, E., Bassaris, H. P., Skoutelis, A. (2000). Pro-versus Anti-inflammatory Cytokine Profile in Patients with Severe Sepsis: A Marker for Prognosis and Future Therapeutic Options. The Journal of Infectious Diseases, 181 (1), 176-180. doi: 10.1086/315214 
[7] Patella, M., Anile, M., Del Porto, P., Diso, D., Pecoraro, Y., Onorati, I. et. al. (2014). Role of cytokine profile in the differential diagnosis between acute lung rejection and pulmonary infections after lung transplantation. European Journal of Cardio-Thoracic Surgery, 47 (6), 1031-1036. doi: 10.1093/ejcts/ezu395

[8] Abouelela, A., Al-Badawy, T., Abdel Gawad, M. (2015). Predictive value of different scoring systems for critically ill patients with hospital acquired pneumonia. Intensive Care Medicine Experimental, 3 (1), A345-A347. doi: 10.1186/2197-425x-3-s1-a345

[9] Rotstein, C., Evans, G., Born, A., Grossman, R., Light, R. B., Magder, S. et. al. (2008). Clinical Practice Guidelines for Hospital-Acquired Pneumonia and Ventilator-Associated Pneumonia in Adults. Canadian Journal of Infectious Diseases and Medical Microbiology, 19 (1), 19-53. doi: 10.1155/2008/593289

[10] Rice, T. W., Wheeler, A. P., Morris, P. E., Paz, H. L., Russell, J. A., Edens, T. R., Bernard, G. R. (2006). Safety and efficacy of affinity-purified, anti-tumor necrosis factor- $\alpha$, ovine fab for injection (CytoFab) in severe sepsis. Critical Care Medicine, 34 (9), 2271-2281. doi: 10.1097/01.ccm.0000230385.82679.34

[11] Spyridaki, A., Raftogiannis, M., Antonopoulou, A., Tsaganos, T., Routsi, C., Baziaka, F. et. al. (2012). Effect of Clarithromycin in Inflammatory Markers of Patients with Ventilator-Associated Pneumonia and Sepsis Caused by Gram-Negative Bacteria: Results from a Randomized Clinical Study. Antimicrobial Agents and Chemotherapy, 56 (7), 3819-3825. doi: 10.1128/aac.05798-11

[12] Taylor, G., Gravel, D., Matlow, A., Embree, J., LeSaux, N. et. al. (2016). Assessing the magnitude and trends in hospital acquired infections in Canadian hospitals through sequential point prevalence surveys. Antimicrobial Resistance \& Infection Control, 5 (1), 19-25. doi: 10.1186/s13756-016-0118-3

[13] Tsaganos, T., Raftogiannis, M., Pratikaki, M., Christodoulou, S., Kotanidou, A., Papadomichelakis, E. et. al. (2016). Clarithromycin Leads to Long-Term Survival and Cost Benefit in Ventilator-Associated Pneumonia and Sepsis. Antimicrobial Agents and Chemotherapy, 60 (6), 3640-3646. doi: 10.1128/aac.02974-15

[14] Gikas, A., Roumbelaki, M., Bagatzouni-Pieridou, D., Alexandrou, M., Zinieri, V., Dimitriadis, I., Kritsotakis, E. I. (2010). Device-associated infections in the intensive care units of Cyprus: results of the first national incidence study. Infection, 38 (3), 165-171. doi: 10.1007/s15010-010-0007-2

[15] Xia, J., Gao, J., Tang, W. (2016). Nosocomial infection and its molecular mechanisms of antibiotic resistance. BioScience Trends, 10 (1), 14-21. doi: 10.5582/bst.2016.01020

[16] Kollef, M. H., Hamilton, C. W., Ernst, F. R. (2012). Economic Impact of Ventilator-Associated Pneumonia in a Large Matched Cohort. Infection Control \& Hospital Epidemiology, 33 (03), 250-256. doi: $10.1086 / 664049$

[17] Van Vught, L. A., Scicluna, B. P., Wiewel, M. A., Hoogendijk, A. J., Klein Klouwenberg, P. M. C., Franitza, M. et. al. (2016). Comparative Analysis of the Host Response to Community-acquired and Hospital-acquired Pneumonia in Critically Ill Patients. American Journal of Respiratory and Critical Care Medicine, 194 (11), 128-133. doi: 10.1164/rccm.201602-0368oc

[18] Micek, S. T., Chew, B., Hampton, N., Kollef, M. H. (2016). A Case-Control Study Assessing the Impact of Nonventilated Hospital-Acquired Pneumonia on Patient Outcomes. Chest, 150 (5), 1008-1014. doi: 10.1016/j.chest.2016.04.009

[19] Mouktaroudi, M., Giamarellos-Bourboulis, E. J. (2012). Macrolides for the therapy of nosocomial infections. Current Opinion in Infectious Diseases, 25 (2), 205-210. doi: 10.1097/qco.0b013e32834ff1b4

[20] Radzikowska, E., Roży, A., Jaguś, P., Wiatr, E., Gawryluk, D., Chorostowska-Wynimko, J., Roszkowski-Śliż, K. (2016). Cryptogenic Organizing Pneumonia: IL-1 $\beta$, IL-6, IL-8, and TGF- $\beta 1$ Serum Concentrations and Response to Clarithromycin Treatment. Advances in Respiratory Cancerogenesis, 911, 77-85. doi: 10.1007/5584_2016_223

[21] Zilberberg, M. D., Shorr, A. F. (2010). Ventilator-Associated Pneumonia: The Clinical Pulmonary Infection Score as a Surrogate for Diagnostics and Outcome. Clinical Infectious Diseases, 51 (S1), S131-S135. doi: 10.1086/653062

[22] Zeng, M., Li, Z.-Y., Ma, J., Cao, P.-P., Wang, H., Cui, Y.-H., Liu, Z. (2015). Clarithromycin and dexamethasone show similar anti-inflammatory effects on distinct phenotypic chronic rhinosinusitis: an explant model study. BMC Immunology, 16 (1), 16-37. doi: 10.1186/s12865-015-0096-x

[23] Eachempati, S. R., Hydo, L. J., Shou, J., Barie, P. S. (2010). The Pathogen of Ventilator-Associated Pneumonia Does Not Influence the Mortality Rate of Surgical Intensive Care Unit Patients Treated with a Rotational Antibiotic System. Surgical Infections, 11 (1), 13-20. doi: 10.1089/sur.2008.025 